\title{
The Economic Impacts of COVID-19 Pandemic on the U.S. Industries
}

\author{
Qingzhi $\mathrm{Li}^{1 *}$, Siqi $\mathrm{Jia}^{2}$, Yitong $\mathrm{Chen}^{3}$, Feier Yang ${ }^{4}$ \\ ${ }^{1}$ Shenzhen College of International Education, Shenzhen, 518000, China \\ ${ }^{2}$ Beijing National Day School, Beijing, 100039, China \\ ${ }^{3}$ Rugao International Academy, Shanghai, 200000, China \\ ${ }^{4}$ Nankai Secondary School, Chongqing 400030, China \\ *Corresponding author. Email: s16008.li@stu.scie.com.cn
}

\begin{abstract}
Since the first U.S. case was reported on January 21, 2020, many American industries have been heavily affected from an economic perspective. This paper primarily gives a literature review on the negative impact of the COVID-19 pandemic on US industries with the help of historical data. To be more specific, this paper detailedly analyzes two industries (Airlines and Hospitality) that suffer from the COVID-19 pandemic to a greater extent compared with other industries. How government reacts to cope with the recession of these industries is also concluded. However, as the COVID-19 pandemic affects diverse industries in various ways, this paper tends to prove that some industries are actually boosted by the global health crisis by giving evidence from the e-commerce industry and pharmaceutical industry. The result indicates that the COVID-19 pandemic affects US markets in a dissatisfactory but creative way. In short, impacts are mostly negative but positive impacts do occur.
\end{abstract}

Keywords: COVID-19 pandemic, U.S. Economy, E-commerce market, Pharmaceutical sector

\section{INTRODUCTION}

At the beginning of the research, some background information was explored. The COVID-19 virus which retrograded the U.S. economy were estimated with uncertain capacity, as the coronavirus ripped through the global world, its effect has been impacted nearly 140,000 Americans[1]. There was a record of the unemployed American welfare applicants, the accounted 3.28 million which the largest quantity ever recorded. In addition, the unemployment rate skyrocketed faster than it during the recession in 2008, it could be a signal for America that the economy would toward in a recession in the coming future. With the consideration of abundant resources, we agreed to select America as the research object.

In the work, tend to understand the hit of COVID-19 on the US economy and consider its effect on different industries, we mentioned to collect some secondary information like the sales revenue and quantities of employment of one corporation, with the primary analysis. In the dissertation, the positive and negative effects would be considered and discussed on four industries: hospitality companies, airline companies, Ecommerce industries, and pharmaceutical companies[2].
Nevertheless, the results of the research would lack objectivity, even those four industries were the leading firms in the U.S., they could not represent the whole economy. Furthermore, the source of data we collected was not unified, which might lead to deviation. Regulations taken by the U.S. government in 2020 and the statistical employment data will generate the outcome of the major direction of attention in the future.

\section{METHODOLOGY}

In this paper, we apply mainly qualitative methods aimed to produce generalized knowledge on the economic impacts of COVID-19 on U.S. industries. COVID-19 is unique in the variety of its impact as it is a humanitarian disaster that has different effects on different industries. Nevertheless, data-driven analyses are accomplished for investigating to what extent industries(hospitality, e-commerce, and pharmaceutical sector) are influenced. The reason why we didn't collect data and analyze them by ourselves when drawing a recapitulatory conclusion on the airline industry is that we found available research results from preceding authoritative research papers and able to use them as a 
powerful tool. We consider sales revenue and numbers of the employee as two indicators for industries' performance. Historical data for numbers of employees in the hospitality and e-commerce sales revenue, obtained from the U.S. Census Bureau (Labor Statistics) and Federal Reserve Economic Data (FRED), serve as two indicators of how industries are influenced by the 2020 global health crisis.

\section{MAIN RESEARH QUESTION}

We observe dramatic changes in society during COVID-19, including people's behaviors, industries' operating mechanisms as well as nation's policy responses. It is significant to figure out the causes of these changes during the pandemic, so we analyze how COVID-19 impacts main industries in the U.S. and also evaluate policy responses to recover these sectors. During the research stage, we find out that the majority of the references talking about the negative impact of the epidemic on American industries. The outbreak and spread of COVID-19 directly lead to job losses and thus causing an increase in the unemployment rate in a large proportion of industries and corporations in the U.S. Besides, some industries need to spend more money on their operating system to ensure health and safety (e.g., body temperature checks, viral tests, etc.). Many vulnerable corporations are even risky to go bankrupt.

However, we notice that several industries, in spite of a relatively small proportion, do experience an increase in total revenue or a decrease in unemployment. For instance, the e-commerce market shows a fast-growing revenue during the pandemic. There is a surge in demand because of anxiety and depression among people caused by the lockdown. Another crucial sector--positively impacted by COVID-19--is the pharmaceutical market. Some top global pharmaceutical markets even display phenomenal growth of employment opportunities. In addition to analyzing the negative consequences that COVID-19 brings to the U.S. main industries, we also focus on several industries being positively impacted by the pandemic.

The following contents analyze the transition of four main industries in the U.S., including the airline industry, hospitality industry, e-commerce, and pharmaceutical sector, which are caused by the epidemic. Their policy responses to these changes will also be a part of our evaluation.

\section{NEGAVTIVE IMPACT}

\subsection{Background}

The COVID-19 has largely influenced the labor market in the U.S. The unemployment rate peaked at an unprecedented level in April 2020, at 14.8\%, since data collection started in 1948, before falling to a still- elevated level in December (6.7\%)[3]. Research has also shown that the figure of long-term unemployment continued to rise slowly, for those who are unemployed for 27 or more weeks. In January 2021, there was an increase in 2.9 million unemployed people compared with January 2020, at 4.0 million and 1.2 million respectively[4]. Long-term unemployment has a scarring effect, which harms jobless people and makes them hard to find new jobs. The speed and depth of recovery would be affected by the scarring effect[5]. In specific, the Covid-19 indeed has huge negative impacts on lots of industries. Industries that depend on the movement of people and in-person contact have crushed a lot, such as hospitality, airline, and tourism. In this paper, we will mainly focus on the negative impacts on the hospitality and airline industry.

\subsection{Hospitality}

The hospitality industry is part of the service industry including a wide range of businesses, providing service and customer satisfaction, which includes areas such as lodging service, entertainment, and food services. The hospitality industry has been devastated a lot in America due to several reasons as listed below. At first, the confinements, rigorous policy, and people's fear of COVID-19 restrict people's willingness and opportunities to travel[6]. There is the closure of attractions and tourism facilities and borders closing, along with the number of airlines decreased for both domestic and foreign flights. Thus, the movement and liquidity of people declined drastically. In the U.S., many hotels claimed that the number of consumer cancellations increased dramatically. According to the data released by the United States Bureau of Labor Statistics (BLS), around 5.5 million people are jobless within the hospitality industry in May 2020. Moreover, the unemployment rate in the hospitality industry in April 2020 is 39\%, and that of $36 \%$ in May 2020[7]. In the past decade, the highest industry unemployment rate was merely $14.2 \%$ in January 2010. Furthermore, Figure 1 represents the number of workers in the hospitality and leisure industry in the U.S. between 2009 and 2020. It illustrates that there was an enormous decrease in the number of employees in this area in 2020 after a continuous increase for more than ten years before.

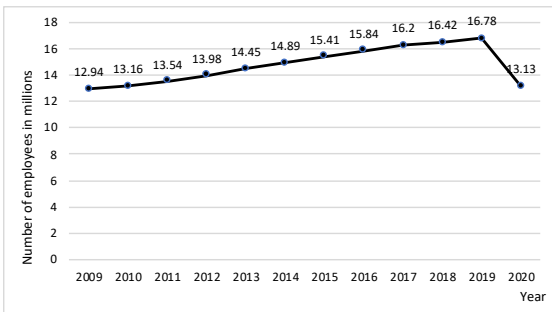

Figure 1 Numbers of employees in the hospitality and leisure industry in the United States from 2009 to 2020(in millions)

Source: Bureau of Labor Statistics 
In addition, there are numerous huge companies in the hospitality industry that are influenced by COVID19, such as Burger King Corp., Starbucks Corp, Inc., Domino's Pizza, Inc., KFC Corp., McDonald's Corp., Marriott International Inc., InterContinental Hotels Group PLC. Marriott International which has about 174,000 employees is planned to furlough thousands of workers $[8,9]$. Besides, revenue per available room in the hospitality industry in the U.S. declined $11.6 \%$ until 7 th March 2020. Because of a significant fall in demand, hotel companies were seeking direct financial help for their staff. Those companies had an estimated loss since February which is about $\$ 1.5$ billion.

\subsection{Airlines}

According to the research conducted by Danny Haydon and Neeraj Kumar[10], the airline industry was one of the five most vulnerable industries during COVID-19 in 2020, along with the oil and gas drilling industry and automotive industry[10]. By analyzing the unemployment and profits of these industries, we find out that the implication on these industries to be a chain reaction. Logically speaking, as a consequence of the outbreak of COVID-19, some cities of the U.S. had to enforce travel restrictions, which heavily attacked the airline industry with the evidence provided by PIIE that air travel reservations in the U.S. reduce approximately two-thirds compared to bookings in last October[11]. The airline industry faces deficits because of higher operating costs--additional health and safety requirements (e.g. disinfection, body temperature checks, or viral detections). As for the automotive industry, the supply chains of cars were disrupted immediately because of the restriction on manufacturing. Besides, sales forecasts for the US estimate that the number of people not buying new cars because of the pandemic will fall by $9 \%$ a year[12]. Consequently, the demand for oil and gas would decrease since the use of civil aircraft and vehicles reduced a lot. We also search for how tourism was impacted in the United States during the pandemic. In 2019, "tourism generated 4.7 percent of GDP, \$1.5 trillion, in the U.S.", meaning that tourism is an important and profitable industry in the U.S. However, in 2020, "tourism has collapsed to between a quarter and a third of its 2019 level across advanced economies"[11]. This data reflects the negative effects caused by COVID19 on tourism, which also relates to the decline of the airline industry.

Without a doubt, the airline industry was a target of policy intervention during COVID-19. The American government provided support consists of direct aid and wage subsidies for air transport. The total monetary value of relief for airlines provided by the American government was over 80 billion USD, as of August 2020[13]. In general, interventions have taken two forms: 1. non-targeted support schemes aimed at providing liquidity to companies irrespective of their activities, including the expansion of existing retention work schemes or the introduction of new ones; 2 . sectoral schemes, including those programs that support airline employees, known in the U.S. as the Payroll Support Programs[13].

\section{POSITIVE IMPACT}

\subsection{E-commerce}

E-commerce is an industry that provides online transactions. The U.S. has the second largest e-commerce market in the world, which is $\$ 685$ billion behind China ( $\$ 1,117$ billion) and $\$ 254.5$ billion ahead of Japan ( $\$ 177.5$ billion), in 2020[14]. Figure 2 shows the ecommerce retails sales for recent two decades.

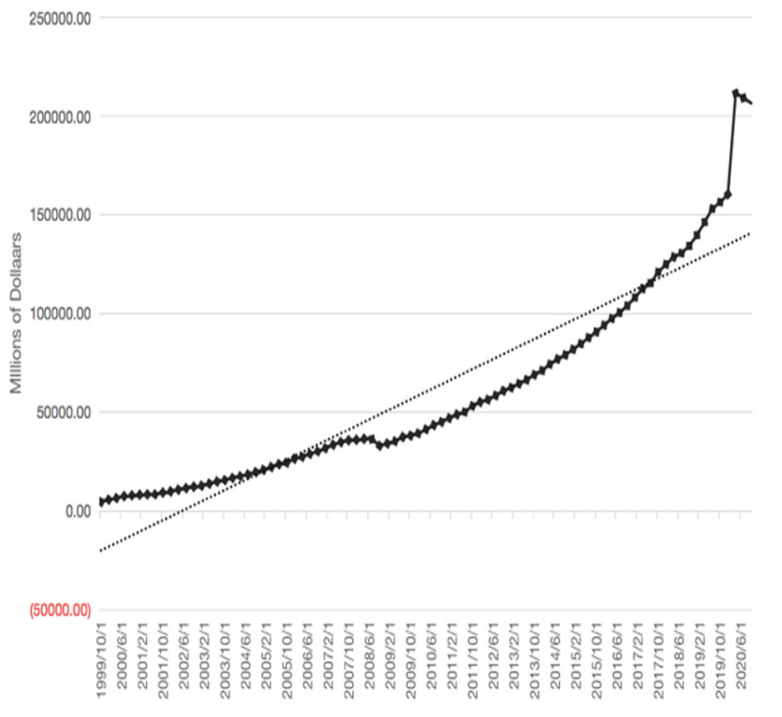

Figure 2 E-commerce Retail Sales(USA)

Note: This graph provides estimates for e-commerce retail sales from the year 2000 to 2020 and its central tendency, based on the data from the Federal Reserve Bank of St.Louis. During the pandemic crisis, the total retail sale revenue in the e-commerce market increased $32.1 \%$ in one year. (\$156,391millions in 2019 to $\$ 206,666$ million in 2020). This is unprecedented expansion as the percentage increasing usually fluctuates around $20 \%$ before the COVID-19 pandemic.

\section{Data Source: FRED}

The most distinct positive impact of the COVID-19 pandemic on the e-commerce market is shown by fastgrowing revenue, which is boosted by increasing demand. Social distancing and closure of stores shift people's purchasing patterns from face-to-face to online delivery[15]. Taking the United States as an example, a surge in demand is caused by people's panic emotion so they tend to purchase a large number of items related to self-protection(e.g. disposable gloves), home activities, 
ICT equipment, groceries, and most importantly, basic survival needs (e.g. canned meat).

Relating to the supply side, another positive outcome is the development of e-commerce businesses as many firms' physical businesses are forced to shut down due to the spread of coronavirus. This is considered as a longrun impact as workers are trained with new skills and firms are equipped with new infrastructure. For instance, according to data from Amazon's grocery branch Whole Food Markets, the Food Market increased its online order capacity by more than $60 \%$ to meet the soaring demand and expand its pickup services from approximately 80 stores to over 150 stores. Figure 3 shows the Amazon Sales revenue for recent 15 years, presenting a strong evidence to prove that e-commerce market is positively influenced.

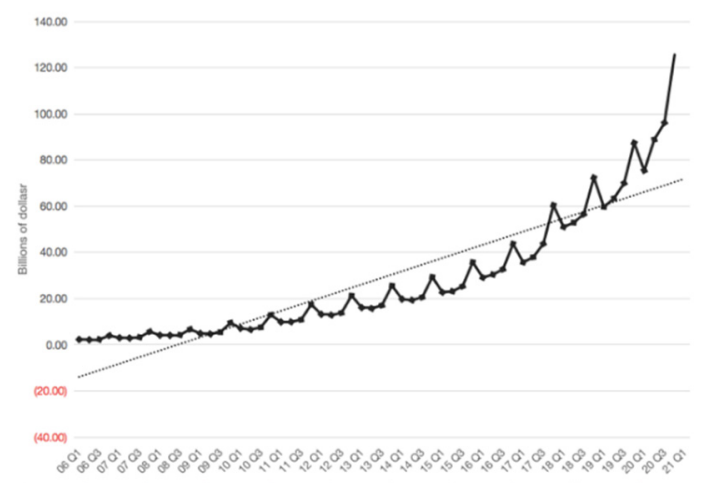

Figure 3 Amazon Sales Revenue

Note: This graph provides estimates for the sales revenue of Amazon, which takes the largest share in the e-commerce industry, from the year 2016 to 2020. The total revenue increased $43.59 \%$ in one-year time (from $\$ 87.347$ billion in 2019 Q4 to $\$ 125.555$ billion in 2020 Q4)

Data Source: microtrends.net

\subsection{Pharmaceutical sector}

Among Johnson \& Jonson's products, their surgery segment generated the most revenue in 2020. According to Figure 4, the sales revenue of Johnson \&Johnson illustrates a consistent increase from 2006 to 2020. Even in 2020, facing the cruelty of the COVID-19 virus, the revenue still rises[16].

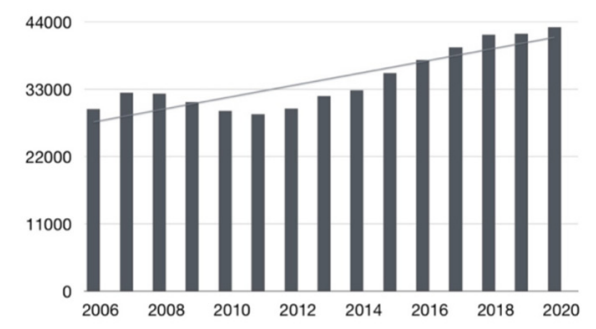

Figure 4 Johnson\&Johnson Sales Revenue(in million dollars)

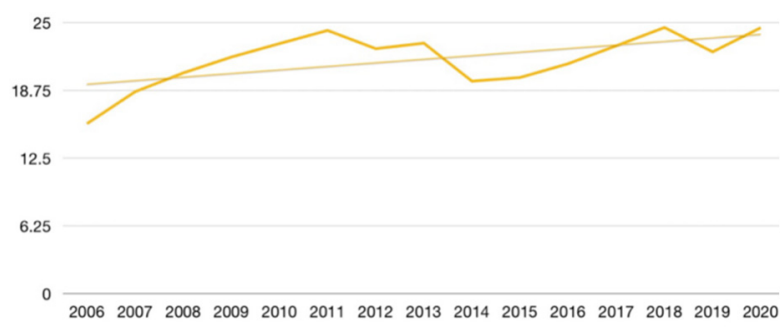

Figure 5 Eli Lily's Sales Revenue(in billion dollars) Source: companiesmarketcap.com

Another pharmaceutical company in the U.S. that used its own technology to lower down the impede of the COVID-19 virus was Eli lily. According to figure 5, it illustrates that during the period from 2006 to 2020, Eli lily's sales revenue approximately doubled. For many insulin-dependent diabetics, Eli lily was fully worried about an unprecedented financial predicament leaving patients unable to access essential medication. Therefore, it has offered supports to unemployed people due to the COVID-19. At that time, patients were encouraged to communicate with the Lilly Diabetes Solution Center, such as announcing restrictions of monthly prescription costs, to ensure the substantial supply of medication. Finally, it is expected that pharmaceutical firms should use their own unique strategy for patients, also companies should better not lead to detrimental effects in the coming future.

\section{CONCLUSION}

This dissertation provided an exposition of the impacts of COVID-19 on U.S. main industries. It suggests that despite the pandemic hit the U.S economy severely for most industries (Hospitality, Airline, Automobile), there are still some positive impacts on several industries (E-commerce, Pharmacy). There are also different degrees of positive or negative impacts on different industries. Although the COVID-19 pandemic hit the U.S. economy disastrously, government should try to reassure and support those injured industries, encourage those industries which have already benefited, and revive the U.S economy.

The U.S. government has already implemented both fiscal and monetary policy to rescue those businesses and industries. For instance, the legislation that the U.S. \$483 billion Paycheck Protection Program (PPP) and Health Care Enhancement Act included $\$ 321$ billion for additional forgivable Small Businesses Administration loans and guarantees to assist small businesses to retain workers, and $\$ 62$ billion for Small Businesses Administration to provide grants and loans to help small companies. Federal Reserve also provided facilities to sustain the credit flow, including Paycheck Protection Program Liquidity Facility (PPPLF) to provide liquidity to financial institutions which directly helps small businesses to keep their workers[17]. 
The vaccines have been invented, and 291 million (Data source: Bloomberg) doses have been administered in the U.S. Lots of restrictions and confinements are removed which means that there are more chances for injured industries to recover their businesses with the help of the government.

\section{REFERENCES}

[1] World Health Organization(2020) Impact of COVID19 on the people's livelihoods, health and food systems. https:/www.who.int/news/item/13-102020-impact-of-covid-19-on-people's-livelihoodstheir-health-and-our-food-systems

[2] Chris Miller (2020) The effect of COVID-19 on the U.S. Economy https:/www.fpri.org/article/2020/03/the-effect-ofcovid-19-on-the-u-s-economy/

[3] Gene Falk, Jameson A. Carter, Isaac A. Nicchitta, Emma C. Nyhof, Paul D. Romero (2021), Unemployment Rates During the COVID-19 Pandemic: In Brief.

[4] Jason Furman (PIIE) and Wilson Powell III (Harvard Kennedy School) (2021), Unemployment continues to fall but workers still not returning to the labor force.

[5] Maya Jollès and Eric Meyermans (2020), Quarterly Report on the Euro Area, 'The structural economic impact of the COVID-19 pandemic on the euro area: a literature review'.

[6] Tom Baum (2020), Hospitality, Tourism, Human Rights and the impact of COVID-19.

[7] Arthur Huang, Christos Makridis, Mark Baker, Marcos Medeiros, Zhishan Guo (2020), Understanding the impact of COVID-19 intervention policies on the hospitality labor market.

[8] (2020), Impact of COVID 19 on the Hospitality Industry, 2020.

https://www.globenewswire.com/fr/newsrelease/2020/04/16/2017204/28124/en/Global-

Hospitality-Market-COVID-19-Most-Affected-

Verticals-Economies-Key-Findings-

Recommendations-Company-Profiles.html.

[9] Maria Nicola, Zaid Alsafi, Catrin Sohrabi, Ahmed Kerwan, Ahmed AI-Jabir, Christos Iosifidis, Maliha Agha, Riaz Agha (2020), The Socio-Economic Implications of the Coronavirus and COVID-19 Pandemic: A Review.

[10] Danny, H., Neeraj, K. (2020) Industries Most and Least Impacted by COVID-19 from a Probability of Default Perspective - September 2020 Update https://www.spglobal.com/marketintelligence/en/newsinsights/blog/industries-most-and-least-impactedby-covid19-from-a-probability-of-defaultperspective-september-2020-update

[11] Simeon, D. (PIIE) (2020) Governments take steps to save tourism from COVID-19 https://www.piie.com/blogs/realtime-economicissues-watch/governments-take-steps-savetourism-covid-19

[12] Accenture (2020) COVID-19: Mobilizing the automotive industry now

https://www.automotiveworld.com/newsreleases/accenture-covid-19-mobilizing-theautomotive-industry-now/

[13] OECD (2020) COVID-19 and the aviation industry: Impact and policy responses

https://www.oecd.org/coronavirus/policyresponses/covid-19-and-the-aviation-industryimpact-and-policy-responses-26d521c1/

[14] Statistia. (2021) E-Commerce Market Analysis The ecommerce market in the U.S. https:/ecommercedb.com/en/reports/country

[15] Census.gov. (2021) US Ecommerce Sales(20112021). https://www.oberlo.com/statistics/usecommerce-sales

[16] Peter Fasolo(2020)How Johnson\&Johnson is supporting its global workforce during COVID-19 https://www.jnj.com/our-company/how-johnsonjohnson-is-supporting-its-global-workforce-duringcovid-19

[17] International Monetary Fund (May 7, 2021), Policy Responses to COVID-19 